\title{
Symptoms of Heat Stress in Tropical and Subtropical Regions on Farm Animals
}

\author{
Alsaied Alnaimy Mostafa Habeeb
}

\begin{abstract}
The thermal relief regions for maximum animals are ranged $4^{\circ} \mathrm{C}$ and $25{ }^{\circ} \mathrm{C}$. In tropical and subtropical countries ambient temperature surpasses $25^{\circ} \mathrm{C}$ and animals undergo high environmental temperatures. Most physiological and biochemical variations in animals could take place to care for essential cell functions in contradiction of stressful conditions and to certification a fast retrieval from modest hypothermic destruction. Animal performance is reduced due to extreme variations in biological purposes affected by heat-stress conditions.
\end{abstract}

Index Terms - Animal, High temperature, production, reproduction, tropical and subtropical areas.

\section{INTRODUCTION ${ }^{1}$}

The summer season in Egypt, as a subtropical country, is categorized by high environmental temperature, high humidity percentage and high solar emission with extreme observed throughout the periods of greatest heat-stress which usually prolongs more than six months from May to October. Animals under such conditions of the hot summer season come to be uncomfortable suffering extremely in their growth, milk production and reproductive traits [1], [2]. However, the best climatic conditions for animals are almost similar an environmental temperature from 13 to $20^{\circ} \mathrm{C}$, wind velocity from 5 to $18 \mathrm{~km} /$ hour, the humidity percentage from 55 to 65 , and a moderate level of sunshine, and these elements are correlated. Environmental temperature is related to other climatic aspects but the relationship with the humidity percentage appears to be the most important. The sensitivity of warmth under high environmental temperature increases with high humidity percentage. Such a relationship was made to suggest a measurement of the level of severity of heat-stress using the two elements and was named the temperature-humidity index (THI). The effect of heat stress is distended when humidity \% is larger than 50 [3].

In tropical and subtropical countries, the climatic representative is the main restriction on the productivity of the farm animals. Production and reproduction are reduced due to the extreme fluctuations in biological roles affected by heat stress conditions [4]. The World Meteorological Organization and the UN Environmental Program stated that

Published on November 12, 2020.

Alsaied Alnaimy Mostafa Habeeb, Prof., Biological Applications Department, Radioisotopes Applications Division, Nuclear Research Center, Atomic Energy Authority, Inshas, Cairo, Egypt.

(e-mail: dr_alnaimy@yahoo.com) worldwide heating would be an extra happening and additional period of exposure to high temperatures, especially, during the months of the summer season.

The natural hyperthermia sometimes occurs during severe high environmental temperature in the summer season due to hard exposure to the sun in the world [5].

\section{CRITICAL ENVIRONMENTAL TEMPERATURES}

After environmental temperatures change out of the comfortable temperature (Thermo-neutral, THN), animals begin to involvement in heat or cold stress conditions. Both stresses necessitate the animal to proliferation the quantity of energy recycled to stay the animal body temperature stable and consequently there is less energy offered for producing their products. THN area is the range of temperatures where animal normal body temperature is kept steady and heat production is at the basal level [6]. The ranges of the THN zone are from lower critical temperature (LCT) to upper critical temperature (UCT). The LCT is the environmental temperature at which animal requirements increase metabolic heat production to stay animal body temperature.

The UCT is the environmental temperature at which the animal rises heat production as a concern of an increase in animal body temperature following for insufficient evaporative heat loss. UCT for growth rates and milk production of Bos Taurus cattle are in the range $21-27^{\circ} \mathrm{C}$ and 24-30 ${ }^{\circ} \mathrm{C}$, respectively and the UCT is given as $25-26{ }^{\circ} \mathrm{C}$, LCT as a range from -16 to $-37^{\circ} \mathrm{C}$ for the animal [7]. In the arid situation, the LCT for newborn animals is $10{ }^{\circ} \mathrm{C}$ and declines by the time to $0{ }^{\circ} \mathrm{C}$ (one month) [8]. However, THN of an animal be influenced by the age, breed, feed intake, diet composition, and the previous state of temperature acclimatization, production, housing system, stand conditions, skin fat insulation, outside coat protection, and the activities of the animal [3], [6].

\section{HEAT GAIN AND HEAT LOSS MECHANISM IN ANIMAL}

Thermoregulation income when the animal sustains its body temperature which includes the balance between heat gain and heat loss. The environmental temperature between lower and upper critical temperature is considered in the region of animal thermoneutrality. Within this region, minimal physiological cost and maximum productivity normally are achieved. Above the upper critical temperature concomitant with the decline of meat, milk and reproductive 
performance have been detected in farm animals, these measures usually are used to point to heat stress [9].

Heat dissipates in animals bodies via varying the rate and depth of blood circulation, by losing water through the skin and sweat glands, and as a last resort, by panting, when blood is heated above $98.6{ }^{\circ} \mathrm{F}$. Sweating cools the animal body through evaporation. High relative humidity percentage delays evaporation, depriving the body of its ability to cool itself. When heat gain exceeds the level the body can remove, body temperature begins to increase [10]. Animals have a sequence of mechanisms to sustain homeostasis. The THN zone is defined as the range of environmental conditions under which an animal can regulate heat loss with the lowest of effort. Changes in environmental temperature modification metabolism and affect the level of heat production and heat loss. If the environmental temperature falls below the LCT, metabolism will increase to augment heat production. If the environmental temperature rises exceeding the evaporative serious temperature, evaporative heat loss increases and food consumption is withdrawn, decreasing metabolism and heat production [11].

\section{DEFINITION OF HEAT STRESS}

Heat-stress is formal at which animal body mechanisms activate to sustain thermal stability when exposed to higher ambient temperature. Heat-stress proceeds when any combination of the environmental conditions reasons the effective temperature of the environment to be higher than the animal's comfort zone [12]. Heat-stress when animal failures the ability to dissipate sufficient heat to maintain thermal balance and consequently body temperature increases and harms dry matter intake, production and reproduction [13]. Heat-stress is definite as the state at which the animal body's physiological mechanisms stimulate to withstand the body's thermal balance when animals are exposed to higher environmental temperatures [14], [15].

Some sequences of risky variations in the biological purposes, including the reduction in feed consumption and feed employment as well as conflicts in water, protein, energy and mineral balances and blood biochemical components ending to deficiency the productive and reproductive performance and depresses normal immunity when exposure the animals to uncomfortable conditions [16], [17]. Due to heat stress conditions, production and reproductive traits in both males and females animals are reduced due to severe changes in most the biological functions which reduction about $50 \%$ from the yield of comfortable breeds when transport to the hot countries [18], [19].

\section{TEMPERATURE-HUMIDITY INDEX (THI)}

The environmental temperature, percentage of humidity, photoperiod, solar radiation and wind velocity appeared to be interrelated in the tropical and subtropical climate. The relationship between the environmental temperature and the humidity percentage seems to be the most important item since the sensitivity of heat rises with increases in the humidity percentage [20]. This relationship planned measurement of the level of the sternness of heat-stress using both environmental temperature and relative humidity and was called the temperature-humidity index (THI). The expressions for describing how animals reply to thermal challenges have been defined by the International Commission for Thermal Physiology [21]. THI used to sign of warm air climatic conditions. THI is a measurement by calculation from the relative humidity and the air temperature and is calculated for a specific day. The THI value is the humidity percentage at any environmental temperature rises and it converts increasingly additional challenging for the animal due to cooling the animal body. According to Kadzere et al. [22] that THI of 70 or lower are reflected in comfortable conditions while THI of 75-78 are revealed a stressful condition and higher than 78 are considered excessive stresses. Several equations used to measure THI indices as signs to heat stress of climatic conditions with relative to the production and reproduction of animals [20]

\section{MECHANISM OF THE HEAT LOSS FROM THE ANIMALS}

An animal has several mechanisms to support dissipate the heat from its body. These mechanisms include conduction (the animal ways heat to any cooler surface), convection (heat streams leave the animal's body), radiation (the animal releases heat to any cooler environment) and evaporation (moisture is evaporated from the external of animal's body through sweating and animal lungs (panting). The animal will also decrease feed intake to produce a lesser amount of metabolic heat which is a protecting mechanism [23]. Higher than the upper critical environmental temperature is associated with the drop in the productive and reproductive traits of animals [11].

When the body of an animal becomes overheated, Guyton [24] clarifying the mechanisms complex in increased heat loss that overheating encourages the thermostatic region to increase the rate of heat loss from the body through three different procedures. The $1^{\text {st }}$ by stimulating the sweat glands to induce evaporative heat loss from the skin or $2^{\text {nd }}$ by stimulating vasodilator nerves to the skin for increasing the transport of the heat by the blood to the body outside or $3^{\text {rd }}$ by stopping sympathetic centers in the posterior hypothalamus to eliminate the normal vasoconstrictor way to the skin vessels for more vasodilatation.

\section{NEGATIVE EFFECTS OF HEAT STRESS CONDITIONS ON THE ANIMAL}

Exposure animals to high air temperature encourage the peripheral warm air receptors to transfer suppressive nerve impulses to the appetite center to decrease the feed consumption for minimizing heat load on animals. Therefore, fewer substrates are converted for hormone synthesis and heat 
production. Feed consumption starts to decline when air temperatures reach of $25-26{ }^{\circ} \mathrm{C}$ and reduce more speedily when air temperatures above $30^{\circ} \mathrm{C}$ and decline by as much as $40 \%$ when air temperatures attained to $40{ }^{\circ} \mathrm{C}$ [25], 22-35\% in goats [26] or $8-10 \%$ in buffalo heifers [27]. Reducing feed intake is the way to decrease heat production in warm situations like the heat increment of feeding is an important cause of heat production in animals [22]. Due to negative energy balance, animal body weight and condition score go depressed [28]. Besides exposure animals to severe heat stress downfall the production of hormone-releasing factors from the hypothalamic centers to decline the pituitary hormonal secretion to depress the secretion of the thyroid hormones finale to deficiency of animal production and reproduction [4]. The high level of cortisol hormone in the animal due to heat stress conditions may be also concomitant in the lower in animal productivity [29].

\section{ANIMAL RESPONSES TO HEAT STRESS CONDITIONS}

Animals commonly respond to stressful conditions via intake fewer diet, thus certainly regulatory the increase in profound body temperature due to digestion. Respiratory rate increases to increase the heat loss by evaporation of water from the lungs. Heat stressed animals also drink the quantity of drinking water at least 5 times higher than under temperate conditions as well as urine excretion increases, and most mineral ions are missing [30]. Exposure of animals to extreme environmental temperature encourages the nerve impulses to the specific centers in the hypothalamus for increasing the evaporative and non-evaporative cooling systems and the adaptive mechanisms to help in avoiding the increase in animal body temperature [14]. Sustained heat exposure falls the level of hormone-releasing factors from the hypothalamic centers and consequently declines in pituitary hormones [4]. These diminutions in both substrate and hormones with an increase in animal body temperature constrain the enzymatic activities, which decrease the metabolism and accordingly deteriorate the production and reproduction of the animal [15].

\section{SYMPTOMS OF HEAT STRESS IN FARM ANIMALS}

1. Reduced activity restlessness and crowding, augmented salivation and decreased the gut and ruminal motility [13].

2. Increased respiration rate: Respiration rate under moderate heat stress are ranges from 80 to $120 \mathrm{bpm}$ while under strong heat stress are ranged from 120 to $160 \mathrm{bpm}$ and under severe heat stress is over $160 \mathrm{bpm} \mathrm{[3].}$

3. Increased rectal temperature: The usual rectal temperature of animals is $101.5 \mathrm{~F}$. Rectal temperature is an indicator of thermal balance and is used to evaluate the adversity of the high ambient temperature. In severe heat stress conditions, the rectal temperature reaches $>102.6 \mathrm{~F}$ and more and is increased when the humidity percentage is greater than $50 \%$. An increase in rectal temperature of $1{ }^{\circ} \mathrm{C}$ or less is sufficient to reduce the productivity of most animals [31].

4. Decreased feed intake: Feed eating decreased by $>10-$ $15 \%$ at $25-27{ }^{\circ} \mathrm{C}$ with a strong decline of $40 \%$ exceeding 30 ${ }^{\circ} \mathrm{C}$ while at $40{ }^{\circ} \mathrm{C}$, the feed eating of animals is reduced by $20-$ $40 \%$. Dry matter intake, gut motility, rumination and ruminal contractions during heat stress are decreased due to depressing animal appetite through the appetite center of the hypothalamus [32].

5. Increased sweating process: Two types of sweating in animals can be illustrious and both are involved in heat dissipation. The first type is insensible sweating or perspiration that leaves the animal body at all times unless the humidity percentage is $100 \%$. The second one is sensible sweating which is the vital evaporative cooling method in the heat-stressed animals [33].

6. Reduced heart rate: The normal panting is $35-45$ breathing while under heat stress, panting increased to $>80$ breaths per minute. The first increase in heart rates slows down when heat stress continues. Reduced heart rate is further common in the heat-stressed animal and is concomitant with the reduced heat production rate as a reaction to great ambient temperatures [4].

7. Increased water consumption: Water consumption in heat-stressed animals increases by 5 times the normal level in temperate regions. Water and trace elements necessity subjective severely by animal demands to withstand homeostasis and homeothermy in heat-stressed animals and lactating animals have a large turnover of water and electrolytes [34]. During the hot period, water intake was at the lowest doubled from the water intake under a comfortable climate due to mainly lower concentrations of metabolic hormones [32].

8. Increased animal water content: The animal body water is estimated to range between $75-81 \%$ of the animal body weight. Heat stress concurrently influences water metabolism [16]. Animals under high environmental temperatures tend to increase the water content in the rumen due to a faster water turnover rate. Water loss from an animal is a continuous process all the time and increases during stressful conditions due to further evaporative water loss. Therefore, water intake of an animal increases progressively with increased environmental temperature [35].

9. Reduced milk production by $10-20 \%$ or more: In tropical and subtropical regions, the heat stress conditions are the main reason for the deterioration of animal productivity with $15 \%$ followed by a decrease in the energy utilization efficiency with $35 \%$ when the animal is transferred from $18^{\circ} \mathrm{C}$ to $30^{\circ} \mathrm{C}$. Deteriorations of animal production are due to decrease feed intake essentially and maybe also due to the adverse effects on the secretory role of the udder [36].

10. Reduced metabolic responses: Under heat-stress, animal metabolism is decreased due to reduced thyroid hormones and growth hormone concentrations as well as ruminal $\mathrm{pH}$ [19].

11. Changes in electrolytes balance: Extreme variations in dietary electrolyte balance and acid/base balance associated 
with heat stress. The main electrolytes are $\mathrm{Na}^{+}, \mathrm{K}^{+}, \mathrm{CL}^{-}$which are the highest ions involved in sweat [37]. Mineral approvals during heat stress include $\mathrm{K}(>1.4 \%), \mathrm{Na}(0.35$ to $0.45 \%) \mathrm{Mg}$ $(0.35$ to $0.40 \%)$ and $\mathrm{Cl}(<0.40 \%)$ of the dry matter intake. Mineral alterations should be prepared several weeks before the beginning of high temperatures, so minerals are existent in the body when needed. Several feed additives, such as buffer and yeast culture have shown benefits when addressing heat stress [38]. Heat stress increases nutritive requirements for the important electrolytes $\left(\mathrm{Na}^{+}, \mathrm{K}^{+}\right.$, and $\left.\mathrm{HCO3}^{-}\right)$and animal sweat contains a large amount of K. Consequently, nutritional electrolyte is important when environmental temperatures exceed $24{ }^{\circ} \mathrm{C}$ and are exacerbated if humidity percentage exceeds 50. The administration of the dietary electrolyte is based on the additional essential body salts and electrolytes to the drinking water or feed. Dietary requirements from the electrolyte's necessity increase to stabilize the dietary electrolyte balance supports homeostasis, contributions the osmoregulation of body fluids, stimulates appetite and confirms normal skeletal progress [2], [38].

12. Increased the evaporative heat loss: Sweating and panting are considered the principal tools for heat loss by evaporation at excessive environmental temperatures. Due to a result of water loss by sweating and panting, thirst is increased, and more urine is excreted and the massive water flux resulting in increased water consumption and loss of electrolytes. In heat-stressed animals, K loss from the skin of animals increases five times and in tries to conserve $\mathrm{K}$, animals increase urinary excretion rates of $\mathrm{Na}$ [4], [19].

13. Respiratory alkalosis: Increasing the panting respiration in heat-stressed animals for increasing the evaporative cooling causing increasing the rapid loss of $\mathrm{Co}_{2}$ resulting in respiratory alkalosis. Animals compensate by increasing the urinary output of $\mathrm{HCO3}^{-}$. Persistent replacement of this ion is serious to the controlling of animal blood biochemistry [14], [15].

14. Oxidative stress: In tropical regions, the effect of heat stress is recognized to induce oxidative stress in the animal due to the high production of reactive oxygen species during the normal metabolic process as well as the decrease in antioxidant protection lead to the many diseases and affects harmfully on animal traits [39]. Oxidative stress in heatstressed animals is separated into two types. The antioxidant enzymes (superoxide dismutase, catalase, and glutathione peroxidase) are the $1^{\text {st }}$ type and the non-enzymatic antioxidants are the $2^{\text {nd }}$ type [40]. The greatest of the negative effects of heat stress is due to enzymatic activity [41]. Heat stress causes a decline in the glutathione level due to reducing glutathione synthesis leading to glutathione insufficiency. The decrease in glutathione and an increase in glutathione oxidative concentrations were detected in the heat-stressed animals (42). Important reserve of total ATPase activity and cholinesterase enzymes were found in heat-stressed animals [43]. Glutathione protects cells from oxidative harm and is accomplished by avoiding damage to important cellular components caused by reactive oxygen species in heat- stressed animals. Glutathione also has been facilitating the early response for attaining tolerance to heat stress [44].

The dietary of antioxidant nutrients is vigorous in protecting tissues in contradiction of free radical damage since free radical responses are an essential portion of normal metabolism. The antioxidant nutrients are improvement the immunity in heat-stressed animals by keeping the structural and functional integrity of the immunity system. The decline in immunity will affect animal production efficiency through amplified susceptibility to diseases, so leading to increased animal disease and death [45]. The antioxidant position provides complementary evidence about the metabolic grade of the animal rather than metabolic parameters alone. The protection against free radical harm by the dietary of antioxidant nutrients has become very important in ruminant production and reproduction [46].

\section{CONClusion}

Under the hot summer season of tropical and subtropical countries, animals are suffering from severe climatic stress and symptoms of heat stress in animals are several.

\section{REFERENCES}

[1] A. A. M. Habeeb, A. A. El-Tarabany, A. E. Gad and M. A. Atta, "Negative Effects of Heat Stress on Physiological and Immunity Responses of Farm Animals," International Technology and Science Publications (ITS),Agricultural Studies, vol.2, no.1, pp.1-18, 2018a. DOI: $10.31058 /$ j.as. 2018.21001.

[2] A. A. M. Habeeb, A. E. Gad , A. A. EL-Tarabany and M. A. A. Atta, "Negative Effects of Heat Stress on Growth and Milk Production of Farm Animals", Journal of Animal Husbandry and Dairy Science, vol. 2, no.1, pp. 1-12, 2018b.

[3] F. Wiersma, "Department of Agricultural Engineering". The University of Arizona, Tucson, 1990. (Cited in Armstrong, 1994).

[4] A.A.M. Habeeb, I.F.M. Marai and T.H. Kamal, "Heat stress, Chapter 2 In Farm Animals and Environment, edited by CJC Philips and D. Piggins, Commonwealth Agriculture Bureau International, Wallingford United Kingdom, pp. 27- 47, 1992.

[5] A. J. McMichael, M. Ando, R. Carcavallo, P. Epstein, A. Haines, G. Jendritsky, L. Kalkstein, S. Kovats, R. Odongo and J. Patz, "Climate change and human health", an assessment by a task group on behalf of the WHO, the World Meteorological Organization, and the United Nations Environment Program, (WHO/EHG/96.7), Geneva, 1996.

[6] A. J. Berman, "Estimates of heat stress relief needs for Holstein dairy cows", Journal of Animal Science, vol. 83, pp.1377-1384, 2005.

[7] A. Berman, Y. M. Folman, M. Kaim, Z. Mamen, D. Herz, A. Wolfenson and Y Grabber, "Upper critical temperatures and forced ventilation effects for high-yielding dairy cows in a tropical climate" Journal Dairy Science, vol. 68 pp.488-495, 1985.

[8] T. Hamada, "Estimation of lower critical temperatures for dry and lactating dairy cows" Journal Dairy Science, vol. 54, PP.1704-1705, 1971.

[9] M. O. Igono, B. J. Steevens, M. D. Shanklin and H. D. Johnson "Spray cooling effects on milk production, milk and rectal temperatures of cows during a moderate temperature summer season", Journal Dairy Science, vol. 68, PP. 979-985, 1985.

[10] R. J. Collier, R. B. Zimbelman, R. P. Rhoads and M. L. Rhoads, "A reevaluation of the impact of temperature humidity index (THI) and black globe humidity index (BGHI) on milk production in high producing dairy cows", Western Dairy Management Conference; March 9-11 Reno, NV., pp. 113-140, 2009.

[11] M. O. Igono, G. Bjotvedt and H. T. Sanford Crane, "Environmental profile and critical temperature effects on milk production of Holstein 
cows in the desert climate", International Journal of Biometeorology, vol. 36, pp. 77-87, 1992, doi: 10.1007/BF01208917.

[12] D. V. Armstrong, "Heat stress interactions with shade and cooling", Journal Dairy Science, vol. 77, pp. 2044-2050, 1994. doi: 10.3168/jds.S0022-0302(94)77149-6.

[13] J. Praks, "The effect of temperature stress on dairy cows". Veterinary ruminants, 2010, (http://www.guaranteed weather. com/page .php? content_id =25).

[14] I. F. M. Marai and A. A. M. Habeeb, "Buffalo's biological functions as affected by heat stress. A review", Livestock Science, vol. 127, pp. 89109, 2010a. doi: 10.1016/j.livsci.2009.08.001.

[15] I. F. M. Marai and A. A. M. Habeeb, "Review: Buffalo's reproductive and productive traits as affected by heat stress," Tropical and Subtropical Agroecosystems vol. 12, pp. $193-217$.

[16] A. A. M. Habeeb, A. E. Gad, F. E. I. Teama and A. A. EL-Tarabany, "Means of Alleviation the Negative Effects of Summer Heat Stress on Animals", Journal of Animal Husbandry and Dairy Science, vol. 2, no. 1, pp. 37-61, 2018a.

[17] A. A. M. Habeeb, A. E. Gad and M. A. A. Atta, "Temperature-Humidity Indices as indicators to heat stress of climatic conditions with relation to production and reproduction of farm animals", International Journal of Biotechnology and Recent Advances, vol. 1, no. 2, pp. 35-50, $2018 \mathrm{~b}$. DOI:10.18689/IJBR-1000107.

[18] A. Agarwal and M. Singh, "Impact of microclimatic modification on the production of dairy animals during summer", Indian Dairyman, vol. 58, pp. 49-59, 2006.

[19] A. A. M. Habeeb, "Negative effects of heat stress conditions during the hot summer season in Egypt on rabbits productivity and alleviation of these effects using some supplementary nutrients", International Journal of Agriculture and Biological Sciences, vol. 3, no. 6, pp. 1-15, 2019. Doi: 10.5281/zenodo. 3613521.

[20] A. A. M. Habeeb, "Impact of climate change in relation to temperature-humidity index on productive and reproductive efficiency of dairy cattle", Boffin Access Limited, International Journal of Veterinary and Animal Medicine, vol. 3, no 1, pp. 124-133, 2020.Doi;10.31021/ijnam.20203124.

[21] International Commission for Thermal Physiology (ICTP), "Glossary of terms for thermal physiology", $3^{\text {rd }}$ eds. Japanese Journal of Physiology, vol. 51, pp. 245-280, 2001

[22] C. T. Kadzere, M. R. Murphy, N. Silanikove and E. Maltz, "Heat stress in lactating dairy cows: A review", Livestock Production Science, vol. 77, pp. 59-91.

[23] J. B. Garner, A. Douglas, A. Williams, A. Wales, A. Marett, B. DiGiacomo, B. Leury B and C. D. Hayes, "Responses of dairy cows to short-term heat stress in controlled-climate chambers", Animal Production Science, vol. 57, no. 7, pp. 1233-1241, 2017.

[24] A. C. Guyton, "Textbook of medical physiology". $3^{\text {rd }}$ (Saunders, W. B., ed.), Co. Philadelphia, pp. 985- 992, 1969.

[25] R. P. Rhoads, L. H. Baumgard, J. K. Suagee and S. R. Sanders, "Nutritional interventions to alleviate the negative consequences of heat stress", Advanced Nutrition, vol. 4, no. 3, pp. 267-276, 2013.

[26] S. Hamzaoui, A. A. K. Salama, G. Caja, E. Albanell, C. Flores and X. Such, "Milk production losses in early lactating dairy goats under heat stress", Journal Dairy Science, vol. 95, no. 2, pp. 672-673, 2012.

[27] O. K. Hooda and S. Singh, "Effect of thermal stress on feed intake, plasma enzymes and blood biochemical in buffalo heifers". Indian Journal of Animal Nutrition, vol. 27, no. 2, pp. 122-127, 2010. https://doi.org/10.1071 /AN16472.

[28] N. Lacetera, U. Bernabucci, B. Ronchi and A. Nardone, "Body condition score, metabolic status and milk production of early lactating dairy cows exposed to a warm environment", Review Agriculture Subtropical and Tropical, vol. 90, no. 1, pp. 43-55, 1996.

[29] A. A. M. Habeeb, M. Kh. Ibrahim and H. M. Yousef, "Blood and milk contents of triiodothyronine $\left(\mathrm{T}_{3}\right)$ and cortisol in lactating buffaloes and changes in milk yield and composition as a function of lactation number and ambient temperature", Arab Journal of Nuclear Sciences and Applications, vol. 33, no. 2, pp. 313-322, 2000.

[30] D. R. Bray and R. Bucklin, "Recommendations for Cooling Systems for Dairy Cattle", Fact Sheet DS-29. University of Florida Cooperative Extension Service, Gainesville, Florida 32611, 1996.

[31] R. E. McDowell, N. W. Hooven and J. K. Camoens, "Effects of climate on performance of Holsteins in the first lactation", Journal Dairy Science, vol. 59, pp. 965-973, 1976.

[32] R. Yasothai, "Effect of climate on nutrient intake and metabolism and countered heat stress by nutritional manipulation", International Journal of Science, Environment and Technology, vol. 3, no. 5, pp.1685-1690, 2014.

[33] A. Chandrahas and K. S. Das, "Heat stress and ameliorative measures in buffaloes", Livestock International, vol. 2, pp. 5-8, 2015.

[34] O. Shalit, E. Maltz, N. Silanikove and A. Berman, "Water, Na, K, and Cl metabolism of dairy cows at the onset of lactation in hot weather", Journal Dairy Science, vol. 74, pp. 1874-1883, 1991.

[35] N. Silanikove, "Effects of water scarcity and hot environment on appetite and digestion in ruminants: a review", Livestock Production Science, vol. 30, pp.175-194, 1992.

[36] N. Silanikove "Effects of heat stress on the welfare of extensively managed domestic ruminants", Livestock Production Science, vol. 67, pp. $1-18,2000$.

[37] U. Farooq, H. A. Samad, F. Shehzad and A. Qayyum, "Physiological responses of cattle to heat stress", World Applied Sciences Journal, vol. 8, pp. 38-43, 2010.

[38] A. M. Abdel-Samee, A. A. M. Habeeb, T. H. Kamal and M. A. AbdelRazik, "The role of urea and mineral mixture supplementation in improving the productivity of heat-stressed Friesian calves in the subtropics. Proceedings of the $3^{\text {rd }}$ Egyptian-British Conference on Animal Fish and Poultry Production, Alexandria University, Alexandria, Egypt, vol. 2, pp. 637- 641, 1989.

[39] J. K. Miller, E. Brzezinska-Slebodzinska and F. C. Madsen, "Oxidative stress, antioxidants, and animal function”, Journal Dairy Science, vol. 76, pp. 2812-2823, 1993.

[40] G. Zalba, G. San Jose, M. U. Moreno, M. A. Fortuno, A. Fortuno, F. J. Beaumont, G. M. A. San José, J. C. Etayo and J. Díez, "Oxidative stress in arterial hypertension: role of NAD (P) H oxidase", Hypertension, vol. 38, pp. 1395-1399, 2001.

[41] U. Bernabucci, B. Ronchi, N. Lacetera and A. Nardone, "Markers of oxidative status in plasma and erythrocytes of transition dairy cows during hot season". Journal Dairy Science, vol. 85, pp. 2173-2179, 2002.

[42] A. A. M. Habeeb, M. N. Sharoud and F. E. I. Teama, "Effect of Pyrosol sprays with and without Taurine on growth and some physiological body functions of rabbits reared under different climatic conditions", International Journal of Applied and Natural Sciences, vol. 3, no. 3, pp. $61-78,2014$

[43] A. A. M. Habeeb, "Biosynthesis and Roles of Glutathione in heat Stressed Animals", International Journal of Scientific Research in Chemistry, vol. 3, no. 5, pp. 91-98, 2018a

[44] A. A. M. Habeeb, "Oxidative Stress in Animals Exposed to Different Stressful Conditions", International Journal of Nutritional Sciences, vol. 3, no. 2, pp. 1027-1029, 2018b.

[45] L. R. McDowell, "Recent advances in minerals and vitamins on the nutrition of lactating cows", Pakistan Journal of Nutrition, vol.1, pp. 819, 2002.

[46] C. Castillo, J. Hernández, M. López-Alonso, M. Miranda and J. L. Benedito, "Values of plasma lipid hydroperoxides and total antioxidant status in healthy dairy cows: preliminary observations", Archiv für Tierzucht, vol. 46, no. 3, pp. 227-233, 2003.

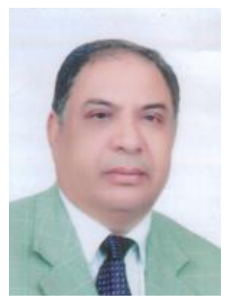

Prof. Dr. Alsaied Alnaimy Mostafa Habeeb

Professor in Animal Science and was a chairman of Biological Applications Department, Radioisotopes Applications Division, Nuclear Research Center, Atomic Energy Authority, Cairo, Egypt. I have 94 published papers in national and 54 published papers in international journals and 7 books and supervisor on 40 Master or $\mathrm{PhD}$ thesis for scientific students in different Egyptian Universities. 